\title{
Self-piercing riveting of aluminium-lithium alloy sheet materials
}

\author{
Xianlian Zhang ${ }^{1)}$, Xiaocong $\mathrm{He}^{1) *}$, Fengshou $\mathrm{Gu}^{2)}$, Andrew Ball ${ }^{2)}$ \\ 1) Innovative Manufacturing Research Centre, Kunming University of Science and Technology, \\ Kunming, 650500, P. R. China \\ 2) Centre for Efficiency and Performance Engineering, University of Huddersfield, Queensgate, \\ Huddersfield, HD1 3DH, UK.
}

\begin{abstract}
The self-piercing riveting (SPR) of 1420 aluminium-lithium alloy sheets is investigated. Static tests with lap-shear loads and fatigue tests using the tension-tension loading mode were applied to obtain the joint performances and failure modes. The mechanism analysis regarding failure and fretting was employed using a scanning electron microscope (SEM) and an energy dispersive X-ray spectroscopy (EDX). The $1420 \mathrm{Al}-\mathrm{Li}$ alloy sheets can be joined effectively using SPR. The fatigue load-fatigue life curve with a $95 \%$ confidence level is obtained using a variation coefficient method. The joints failed in the rivet pulled out from the locked sheet in static trials, and the locked sheet fractured during the fatigue tests. The fretting wear can be observed at the contact interface between the rivet tail and the locked sheet or between both sheets at different load levels. The fretting region changes at a high or low load level, and it is highly relevant to the fatigue rupture paths.
\end{abstract}

Keywords: Self-piercing riveting; Aluminium-lithium alloy; Fretting wear.

\footnotetext{
*Corresponding author: Tel. : +86-871-65930928

E-mail address: x_he@kmust.edu.cn
} 


\section{Introduction}

Aircraft structures using Al-Li alloys are typically fabricated using traditional riveting (Rioja and Liu, 2012), laser beam welding (LBW) (Fu et al., 2014), adhesive bonding (Abrahami et al., 2017), mechanical clinching (He, 2017), friction stir welding (FSW) (Gibson et al., 2015); nevertheless, super plastic forming (SPF) and fibre metal laminates (FMLs) based on Al-Li alloys are also considered ( $\mathrm{Li}$ et al., 2016). The primary shortcomings of these processes are the complicated operation, low efficiency and high costs. And further improvements are difficult to perform on these extensively studied technologies (Mucha, 2013). To ameliorate these limitations, a novel technique called self-piercing riveting (SPR) has been rapidly developed, with significant research value and prosperous application foreground in aerospace, automotive, packaging, and appliance industries ( $\mathrm{Li}$ et al., 2017). SPR is a cold-forming mechanical connecting approach applied to connect multiple layers of similar or dissimilar plate materials (Briskham et al., 2006), and it depends on a mechanical interlock formed by punching a semi-tubular rivet penetrating into the upper plates and partially penetrating and locking into the lower plates (Haque, 2018). SPR presents many advantages including environmental safety, low energy consumptions, relatively low costs, and convenience for process monitoring and automation (He et al., 2008).

Di Franco et al. (2012) studied the SPR process for joining dissimilar sheet materials between carbon fibre panels and AA2024 blanks. Later, they discussed the impact of the distance of two rivets on the joint properties and concluded that the joints with a range of $60 \mathrm{~mm}$ between the rivets presented a better static and fatigue behaviour compared with the distance of $30 \mathrm{~mm}$ and 45 $\mathrm{mm}$. Xie et al. (2018) studied the self-piercing riveting process for component connections in the thin-walled steel structures, and proposed a quality evolution standard and a design calculation method of shear strength with a certain reasonability and reliability. Zhang and Yang (2014) systematically investigated the SPR processes for joining $5754 \mathrm{Al}$ alloy sheets, PA6 plates, and PA6 composite plates with fibre reinforcements; they discovered that these materials could be connected using SPR effectively. Zhang et al. (2016) investigated the SPR process of titanium (Ti) alloy TA1, discussed the effect of heat treatment on the mechanical behaviours of SPR joints, and reported that stress relief annealing was crucial on the fatigue properties but had little effect on the static properties of similar SPR joints in Ti alloy plates. He et al. (2015) studied SPR processes for joining similar or dissimilar sheet materials in $\mathrm{Al}$ alloy 5052 and copper alloy H62, and further analysed the mechanical performances, failure modes and fracture mechanisms of these joints in detail. Liu et al. (2017) investigated the SPR process for joining metal foam sandwich structures in $\mathrm{Al}$ alloys; they found that the joints embedded with nickel foam exhibited a preferable mechanical property and the failure modes were primarily the rivet separated from the lower sheet. Fratini and Ruisi (2009) investigated the hybrid SPR joints between composite panels and Al alloys in detail. Here, the composite plates consisted of the epoxy resin, cure agent, as well as fibreglass panels, and the $\mathrm{Al}$ alloys were AA6082-T6. Finally, they concluded that SPR could be effectively used to connect these materials when the composite panels were regarded as the top of the joint.

Porcaro et al. (2006) presented the static behaviours of SPR joints in Al alloy AA6060 under three different loading directions using an experimental study; they found that the maximum force was primarily influenced by the bottom sheet thickness and the mechanical performances of both sheets in the pure pull-out loading condition $\left(90^{\circ}\right)$, while influenced by the sheet thickness and mechanical performances of both sheets in the pure shear loading condition $\left(0^{\circ}\right)$. Rao et al. (2018) 
reported the fatigue property of SPR joints in CFRP-to-AA6111 Al alloy in lap-shear and cross-tension specimens, and they developed a master curve to predict the fatigue life of the SPR joints for both specimen types. Fu and Mallick (2003) studied the property of self-piercing riveted joints in 6111-T4 aluminium sheets, and analysed the fatigue failure mechanism in detail. They concluded that the rivet setting pressure influences the static failure load, but not the fatigue life. Sun et al. (2007) summarized the fatigue behaviours of SPR joints between similar and dissimilar sheets of AA5182 and HSLA350. And the influences of material grades, material thickness, piercing direction and the use of structural adhesive on the SPR joints were analysed in detail. Xing et al. (2014) investigated the mechanical and failure performances of single-rivet or multiple-rivet SPR joints in Al5052 alloys, and concluded that the static property, fatigue life and ductility of the joints in Al5052 alloys were significantly influenced by the number and distribution patterns of the rivets. Huang et al. (2016) reported the fatigue behaviours for the joints in AA6111-T4 and HSLA340 plates with different sheet thicknesses, and found that the joints dominantly failed in the $\mathrm{Al}$ sheets at low loading levels and in the rivet at higher loading levels. Furthermore, they analysed the fretting mechanisms of the joints in detail utilising SEM and EDX, and concluded that fretting wear might be crucial in the initiation of fatigue cracks.

Durandet et al. (2010) reported that laser-assisted SPR could join magnesium alloy AZ31 and found that the joints without cracks could be obtained at the moment of rivet insertion with temperatures over $200{ }^{\circ} \mathrm{C}$ and the joint properties were clearly affected owing to the length and hardness of the rivet. Meanwhile, Ueda et al. (2012) proposed a modified SPR to mechanically fasten quasi-isotropic CFRP laminates, which was composed of a rivet shank and two plain washers, and they considered that this optimised SPR would be one of the effective joining techniques for CFRP vehicle bodies in future mass-production. Lou et al. (2013) developed a specific technique named electro-plastic self-piercing riveting (EP-SPR) to connect $\mathrm{Al}$ alloys with advanced high strength steels (AHSS). They found that compared with conventional SPR joints, the relevant static strengths of the EP-SPR joints were significantly increased when AHSS acted as the lower sheets. Liu et al. (2016) designed a solid phase connecting technique called friction self-piercing riveting (F-SPR) to connect dissimilar materials of AA7075-T6 alloy sheets and AZ31B magnesium alloy sheets, and the major F-SPR parameters were investigated; they found that the axial force and torque could be reduced with fast rotation speed and low punching speed, and the corresponding low axial force resulted in a small interlock. Tassler et al. (2018) presented a 2D axial symmetrical simulation model and made a robustness analysis to design the joining points for the purpose of no impermissible effects on the result quantities in terms of specified scatter input variables. Haque et al. (2015) developed a simple and effective model to estimate the riveting qualities without cutting the SPR joints in the steel sheets, and attempted to build a linear relationship that operates in a range of sheet thicknesses.

The SPR process for joining similar $1420 \mathrm{Al}-\mathrm{Li}$ alloy panels and its fretting wear were presented in this work. A battery of mechanical experiments were employed to obtain the static and fatigue behaviours of the corresponding joints. A reliable fatigue load-fatigue life curve was achieved using the variation coefficient method. The failure modes were discussed in detail from macro and micro aspects. The typical contact interfaces were investigated using microscopic techniques of SEM and EDX to further analyse the fretting mechanisms. 


\section{Experimental work}

\subsection{SPR tests}

$1420 \mathrm{Al}-\mathrm{Li}$ alloy sheets were used as the sheet materials of the SPR joints, and all sheet materials were sheared along the rolling direction to the following dimensions: $110 \mathrm{~mm} \times 20 \mathrm{~mm}$ $\times 1.5 \mathrm{~mm}$. The specimen dimensions were based on the welding standards: GB/T 2649-89 and GB/T 2651-89. Table 1 presents the chemical compositions of $1420 \mathrm{Al}-\mathrm{Li}$ alloy sheets. Its mechanical properties were obtained using the MTS 634.31F-24 extensometer on the MTS servo-hydraulic test machine. It possesses the ultimate tensile strength of $364.6 \mathrm{MPa}$, yield strength of $295 \mathrm{MPa}$, elastic modulus of $69 \mathrm{GPa}$, and elongation of $14.2 \%$.

Table 1. Compositions of 1420 Al-Li alloy (\%).

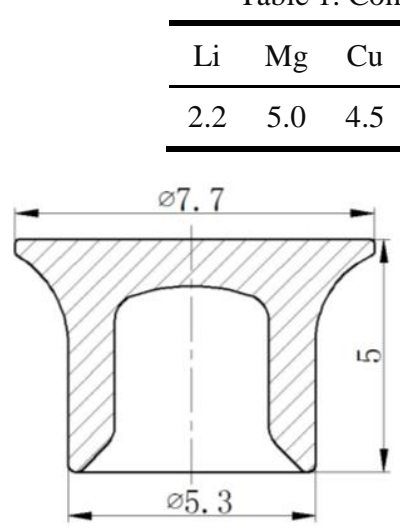

(a) Rivet

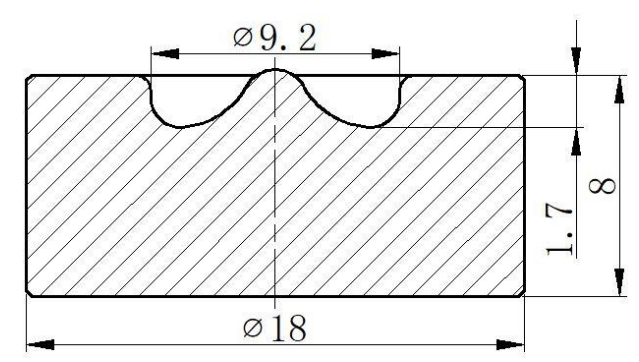

(b) Die

Fig. 1. Configuration of SPR tools (dimensions in $\mathrm{mm}$ )

SPR experiments were conducted on a servo-driven riveting machine, RIVSET VARIO-FC (MTF) fabricated by Böllhoff (Germany). All the riveting tools: punch, rivet and die (Fig.1) were also provided by Böllhoff $\mathrm{GmbH} \& \mathrm{Co}$. The rivets were fabricated from boron alloyed steel $36 \mathrm{MnB} 4$ and coated with zinc-tin alloy. The sheet materials of $1420 \mathrm{Al}-\mathrm{Li}$ alloys were riveted through a series of comparative trials. The joining quality was evaluated using three parameters: rivet head height, rivet spread, and the remaining bottom thickness through the cross sections (He et al., 2015). From the red lines marked in Fig.2, the values of the three parameters could be found. The cross section in Fig. 2 was regarded as the best forming one and the joining quality was reasonably well. A batch of single-lap SPR joints in $1420 \mathrm{Al}-\mathrm{Li}$ alloys (AL1420 joints for short) were manufactured using the following joining parameters: riveting pressure of 190 bar, rivet length of $5 \mathrm{~mm}$, rivet hardness of $44 \pm 2 \mathrm{HRC}$.

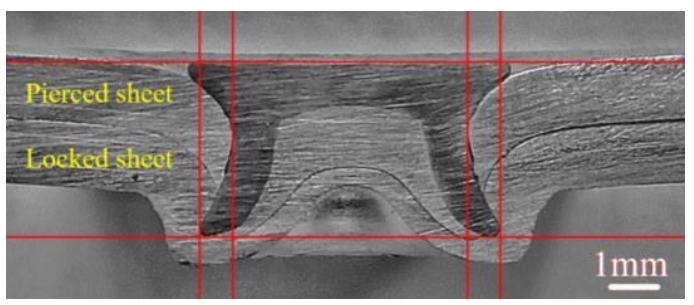

Fig. 2. Cross section of SPR joints in 1420 Al-Li alloy 


\subsection{Static test}

All mechanical experiments were conducted on the MTS servo-hydraulic testing machine. The experimental setup of the AL1420 joints is shown in Fig. 3. For reducing additional bending and centralising the loading direction, spacers with equal sheet thicknesses of $1.5 \mathrm{~mm}$ were attached on both ends of the samples. Lap-shear tests were implemented under a tensile speed of $5 \mathrm{~mm} / \mathrm{min}$. Ten samples were repeated for the lap-shear tests.

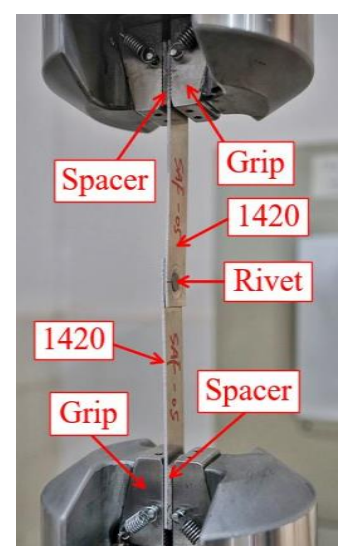

Fig. 3. Diagram of mechanical test setup

\subsection{Fatigue test}

Based on results of the lap-shear tests, fatigue tests were conducted at $10 \mathrm{~Hz}$ using a sinusoidal wave under the tension-tension loading mode. Attaining over 2 million cycles or the appearance of visible cracks was regarded as the termination criterion. The load ratio $R$ of 0.1 was used for all samples. The fatigue load level is up to the results of the pre-tensile tests, and different types of SPR joints have their own characteristics. The $F-N$ curve need to be fitted with the proper data dispersion, so that it can reflect the fatigue life in its entirety. The fatigue cycles of $10^{4}, 10^{5}$ and $10^{6}$ need to be obtained using the suitable fatigue load levels. Therefore, four load levels of $50 \%$, $30 \%, 27 \%$, and $25 \%$ were adopted for the tests, and at least three samples were measured at different load levels.

\section{Results and discussion}

\subsection{Data validation}

For the fatigue tests, the fatigue cycles at each load level were estimated using the variation coefficient (VC) method (Gao, 1981), which is based on the student $t$ distribution. This method was performed based on the following equation:

$$
\frac{s}{x}=\frac{\delta \sqrt{n}}{t_{\alpha}}
$$

where $s$ is the sample standard deviation, $\bar{x}$ is the sample mean, $n$ is the calculated sample value, $\delta$ is the error limit, and $t_{\alpha}$ is the $t$ distribution value. And $t_{\alpha}$ can be found in the table of $\mathrm{t}$ distribution according to the given confidence level and the degree of freedom: 


$$
v=n^{*}-1
$$

where $v$ is the degree of freedom, and $n^{*}$ is the current sample size. When $n \leq n^{*}$, the fatigue data was qualified; when $n>n^{*}$, the number of specimens should be increased to $n^{*}+1$, and then verify the fatigue data again.

Based on the VC method, the number of specimens could be calculated to reach the given confidence level. The reliability of the fatigue data could be improved effectively. In this work, the given confidence level and the error limit were given as $\gamma=95 \%$ and $\delta=0.05$, respectively. Every three samples were tested at the load levels of $50 \%$ and $25 \%$, and every four samples were tested at the load levels of $30 \%$ and $27 \%$.

\subsection{Mechanical performance}

\subsubsection{Static property and failure mode}

The lap-shear test results of AL1420 joints are summarised in Table 2 and Fig. 4. As shown, the overlap ratio in these curves is high and the peak loads and failure displacements are relatively stable. In terms of the calculations using MATLAB 2014b, the average peak load was $6.03 \mathrm{kN}$ (Standard deviation value: $0.22 \mathrm{kN}$ ), which is superior to those of single-lap SPR joints in similar sheet thickness of A15052 Al alloys, H62 copper alloys (He et al., 2015) and TA1 Ti alloys (Zhao et al., 2017) reported in previous papers. According to the methodology proposed by $\mathrm{He}$ et al. (2014), the energy absorption value was obtained, in which a high level of $16.84 \mathrm{~J}$ (Standard deviation value: $0.88 \mathrm{~J}$ ) was obtained.

Table 2. The lap-shear test results of AL1420 joints.

\begin{tabular}{ccccccccccc}
\hline Sample No. & 01 & 02 & 03 & 04 & 05 & 06 & 07 & 08 & 09 & 10 \\
\hline Peak load / $k N$ & 6.26 & 6.26 & 5.89 & 5.80 & 5.75 & 6.36 & 6.03 & 5.81 & 5.96 & 6.16 \\
\hline Failure displacement / $\mathrm{mm}$ & 5.19 & 4.80 & 5.28 & 4.94 & 5.27 & 4.89 & 5.19 & 4.67 & 5.16 & 4.83 \\
\hline
\end{tabular}

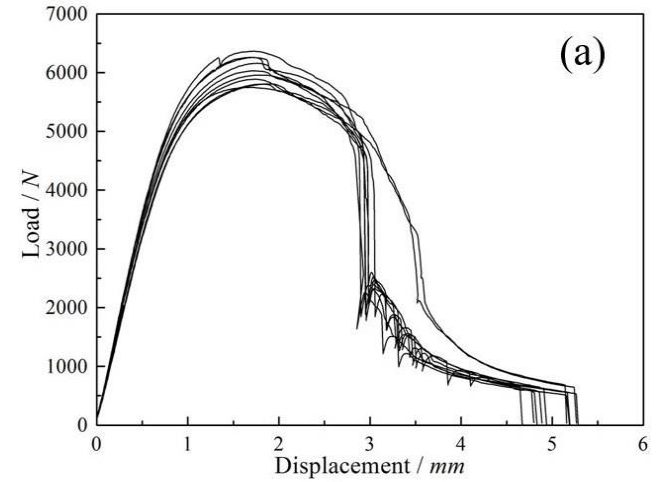

(a) Load-displacement curves

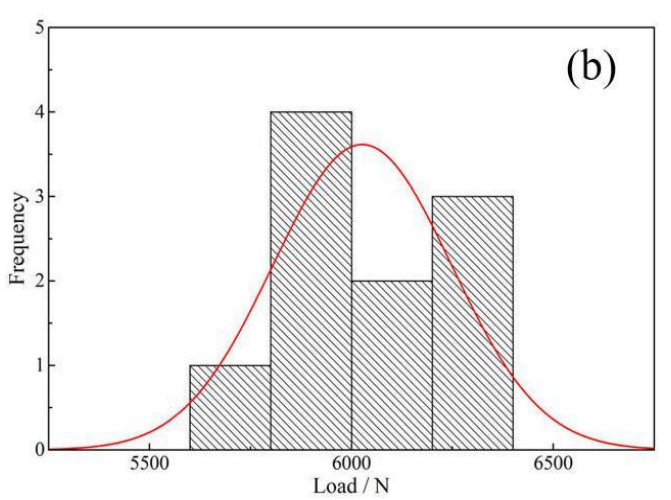

(b) Histogram of peak loads

Fig. 4. Lap-shear results of AL1420 joints

All static failure modes of these joints occurred by rivet pull-out from the bottom sheet, as presented in Fig. 5. And the situation is consistence with the previous research by Haque et al., 2016. It is clear from Fig. 5(a) that a serious warp occurred in the pierced sheet and the wearing phenomena occurred near the rivet hole, as marked in areas A and B. The mechanical interlock was damaged because of the sustained lap-shear loads. The tearing crack can be observed 
distinctly near the riveting hole on the pierced sheet, as illustrated in Fig. 5(b). It is noteworthy that the critical pressure point is on the inner side of the AL1420 joints. The serious warping and wearing appearances caused the energy absorption to maintain at a high level.

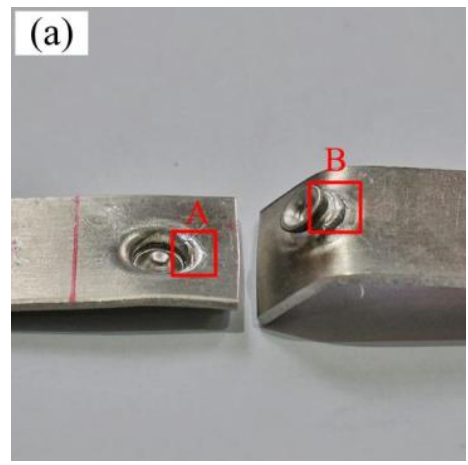

(a) A macroscopic failed sample

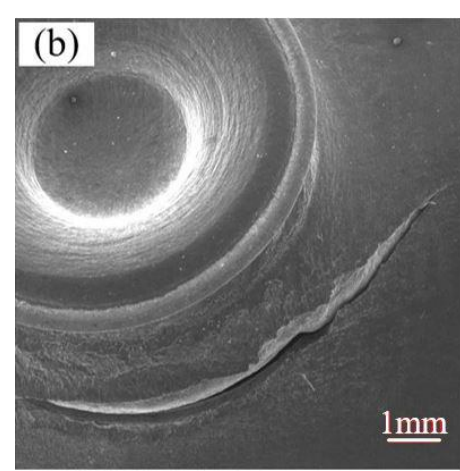

(b) An enlarged image of area B

Fig. 5. Static failure mode of AL1420 joints

\subsubsection{Fatigue results}

The fatigue data are scattered and the $F-N$ curve with $95 \%$ confidence level is fitted using the curve tracing method point by point, as summarised in Fig. 6 . The fatigue cycles increased with the decreasing load level. As shown, the AL1420 joints had average fatigue cycles of 38964, $193860,562758,1001070$ at load levels of $50 \%(3.01 \mathrm{kN}), 30 \%(1.81 \mathrm{kN}), 27 \%(1.63 \mathrm{kN}), 25 \%$ $(1.51 \mathrm{kN})$, respectively. Compared with the SPR joints in other metal sheets in the previous works, the fatigue property of the AL1420 joints is better than that of the SPR joints in similar Al5052 alloys (Zhao et al., 2017), slightly inferior to the SPR joints in similar TA1 alloys, and significantly weaker than the SPR joints in similar H62 alloys (He et al., 2015). The fatigue limit of the AL1420 joints can reach nearly $1.5 \mathrm{kN}$ from the trend of the $F-N$ curve.

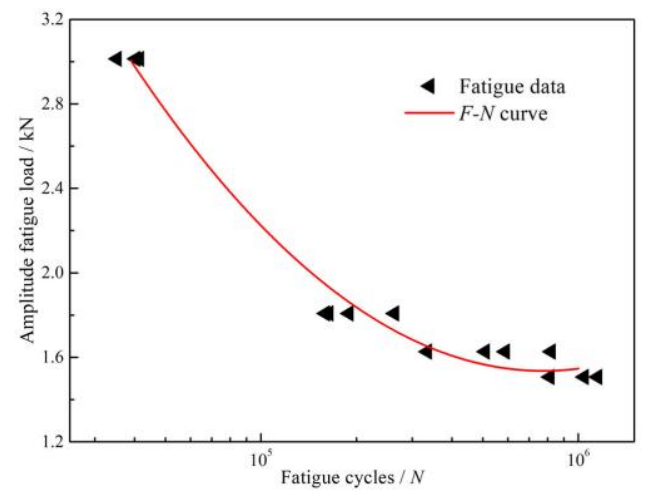

Fig. 6. $F-N$ curve of AL1420 joints

Several samples of fatigue failures are presented in Fig. 7(a). Overall, it was observed that all samples failed by fracture in the locked sheet in the fatigue tests. In detail, the failure modes varied with the load level. The locked sheet fractured through the button at load levels of $50 \%$ and $30 \%$, as illustrated in Fig. 7(b). At load levels of $27 \%$ and $25 \%$, the locked sheet fractured along the button, as shown in Fig. 7(c).

To analyse the fatigue failure mechanisms of AL1420 joints, the failed AL1420 joints at 
different load levels were selected for SEM observation. It was found that the microstructures for the fracture of the locked sheet at different load levels were quite similar. Therefore, the typical SEM images for the fractures are taken as an example, as shown in Fig. 8. Cleavage step-like striations are frequently found from the SEM image of point R in Fig. 8(a). This microstructure exhibits the typical feature of brittle transcrystalline rupture and belongs to the crack propagation region. Fig. 8(b) reveals an SEM image of point $\mathrm{L}$ on the other side of the button, from which many dimples and tearing ridges can be clearly observed. This microstructure exhibits the typical ductile fracture pattern that belongs to the ultimate rupture zone in the fatigue process. It is thought that the locked sheets of the AL1420 joints are broken as brittle ruptures on one side of the button. Subsequently, the fatigue cracks propagate to the other side of the button, and ultimately lead to the ductile rupture of the locked sheet (Zhang et al., 2016).

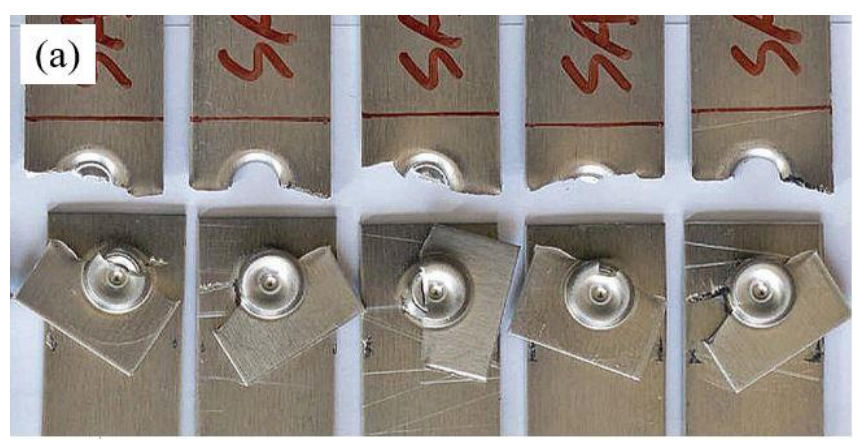

(a) Failed samples

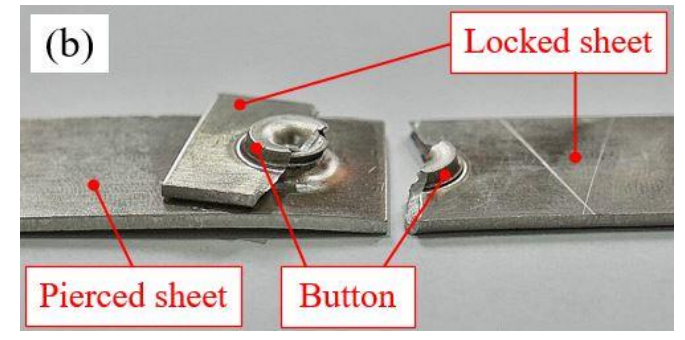

(b) Failure mode at load levels of 50\% and 30\%

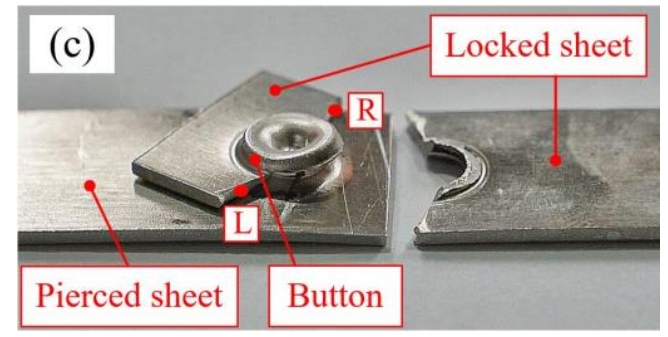

(c) Failure mode at load levels of $27 \%$ and $25 \%$

Fig. 7. Fatigue failure modes of AL1420 joints

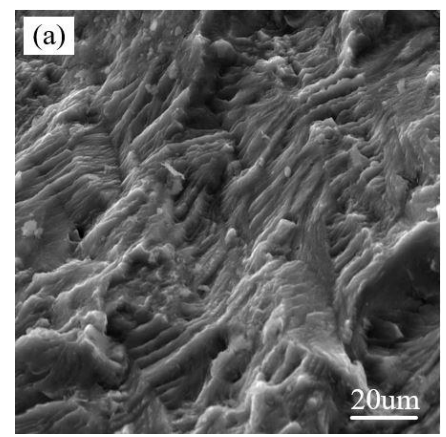

(a) Point R in Fig. 7(c)

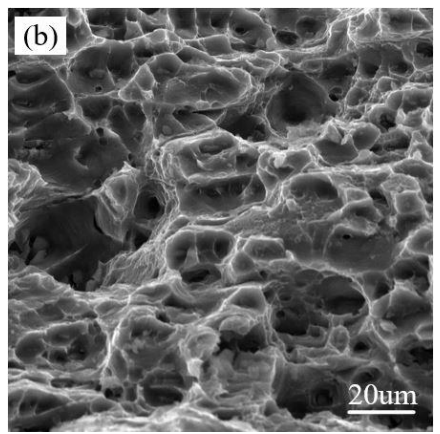

(b) Point L in Fig. 7(c)

Fig. 8. SEM images of failed AL1420 joints 


\subsection{Fretting mechanism}

Fig. 7 shows that the AL1420 joints failed owing to the locked sheet that is broken through the button at high load levels of 50\% and 30\% and along the button at low load levels of $27 \%$ and 25\%. Severe fretting wear can be observed at different regions of the fractured joints (Han et al., 2006). SEM and EDX techniques were performed to analyse the fretting fatigue mechanisms. The primary fretting regions (Chen et al., 2003) and rupture paths of the AL1420 joints are marked in a schematic diagram as shown in Fig. 9. In this section, the rivets were extracted from the failed joints using the laser cutting, so that the rivet surface can be detected using SEM.

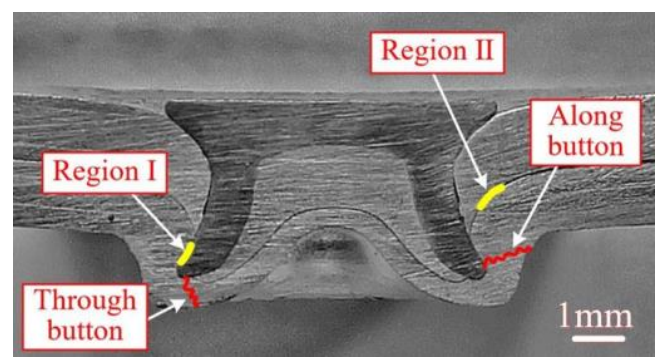

Fig. 9. Diagram of fretting regions and rupture paths

\subsubsection{Fretting at high load level}

The fretting wear of a typical rivet at a high load level is depicted in Fig. 10. A significant amount of fretting debris can be observed clearly on almost the entire rivet surface that was contacted with both sheets, as shown in Fig. 10(a). Fig. 10(b) presents the SEM micrograph of region A near the rivet tail. Severe wear occurred, and an extraordinarily rough surface occurred in the region. Region B marked in Fig. 10(b) was chosen for an examination using EDX with a beam voltage of $30 \mathrm{kV}$. As shown in Fig. 11, the constituents of the fretting debris in region B contained some Al, O, Fe, Zn, Sn, and other elements in an infinitesimal quantity. Fig. 11 exhibits the distribution of different elements directly. The large number of aluminium was derived from the locked AL1420 sheet, and the components of Fe, Zn, and Sn originated in the steel rivet coated with the zinc-tin alloy. The fretting metallic oxides on the rivet surface were caused by the persistent cyclic fatigue loading and micro-vibrations between the rivet and both sheets.

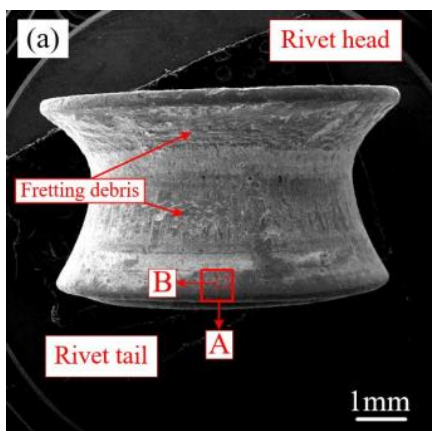

(a) Fretting wear on the rivet

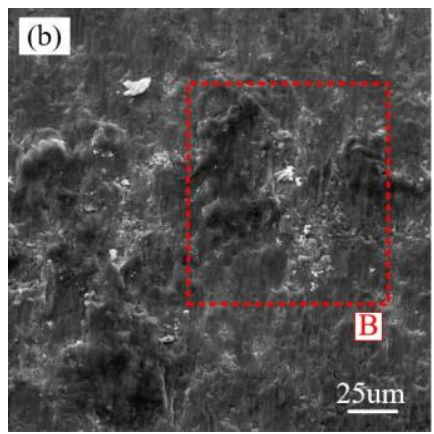

(b) Fretting debris in region A

Fig. 10. A typical rivet surface at high load level

A typical fractured locked sheet at a high load level was considered for further analysis, as illustrated in Fig. 12(a). Serious fretting wear arose in region I, as labelled in Fig. 9. Numerous 
fretting debris and wear traces, especially in region C, as presented in Fig. 12(b), can be seen easily. It is a result of continuous cyclic load and micro-vibrations. Additionally, a tiny fatigue crack along the button, as the rupture path marked in Fig. 9, can be observed, as denoted region D in Fig. 12(a). It is thought that at a high load level, the fatigue crack initiated at the contact interface of the rivet tail and locked sheet because of the fretting wear, and subsequently propagated slowly along the button but rapidly through the button (Khanna et al., 2006). Finally, the locked sheet fractured through the button at a high load level.
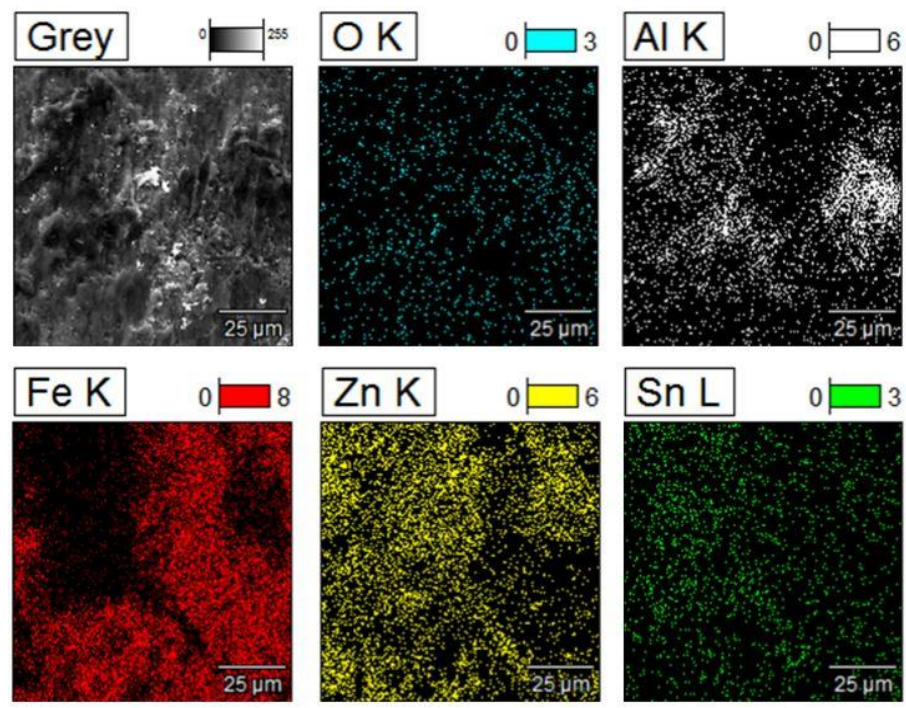

Fig. 11. Energy spectrum of region B marked in Fig. 10(b)

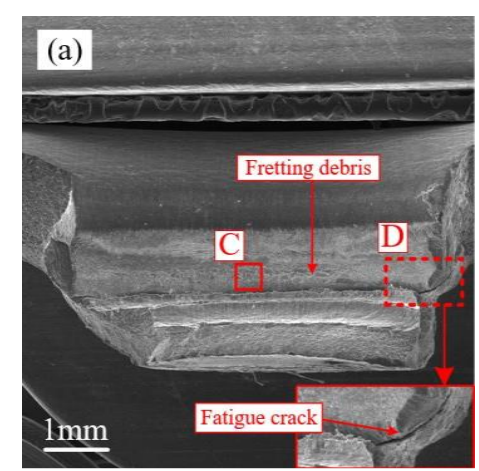

(a) Fretting wear on fractured locked sheet

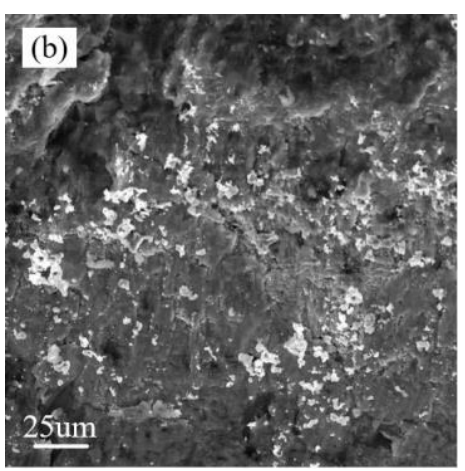

(b) Fretting debris in region $\mathrm{C}$

Fig. 12. A typical locked sheet fracture surface at high load level

\subsubsection{Fretting at low load level}

A typical rivet surface and a locked sheet fracture at a low load level were selected for SEM observation, as shown in Fig. 13. Similar to the fretting at a high load level, a significant amount of fretting debris occurred on the contact interface of the rivet and on both sheets at a low load level. However, almost no signs of wear and no debris particles could be observed from Fig. 13(b), region E next to the rivet tail. Compared to the SEM image (region A near the rivet tail) in Fig. 10(b), where the signs of wear and debris particles could be found clearly, it is thought that the fretting wear of region A is more serious than that of region E. In addition, Fig. 13(c) shows that 
the button part has completely separated from the locked sheet. From the enlarged image of region F, it is concluded that the fretting wear is significantly negligible compared to that in Fig. 12(b).

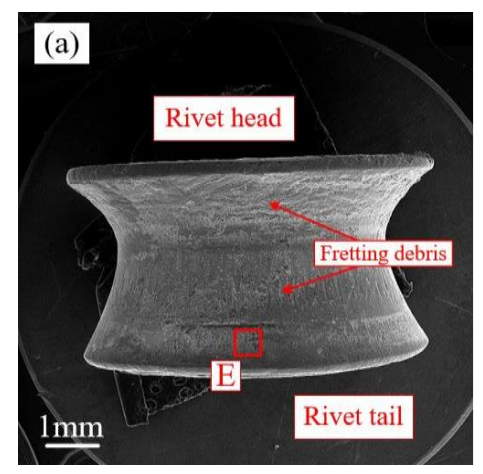

(a) Fretting wear on the rivet

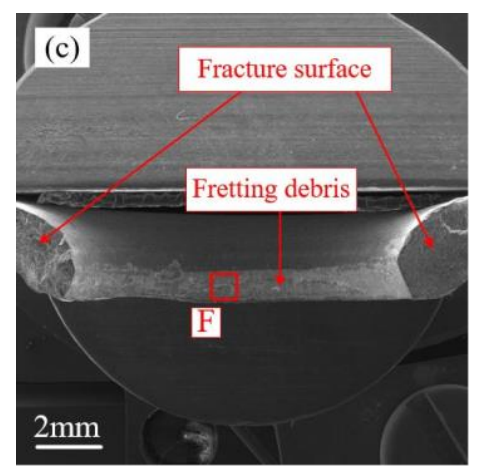

(c) Fretting wear on the locked sheet

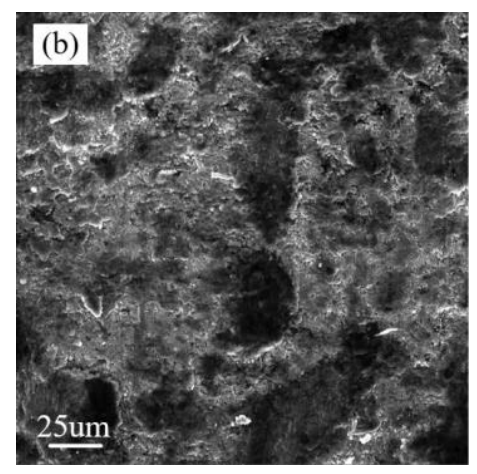

(b) Fretting debris in region $\mathrm{E}$

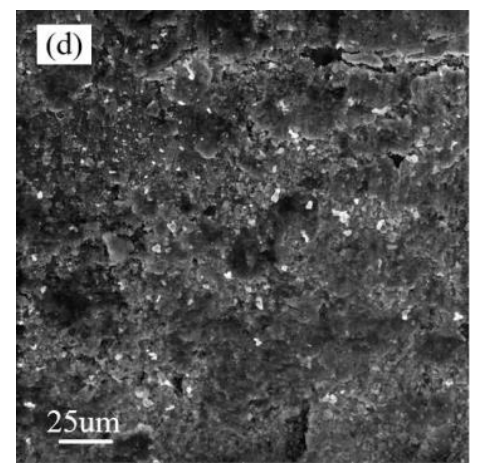

(d) Fretting debris in region $\mathrm{F}$

Fig. 13. Fretting wear between the rivet and locked sheet at low load level

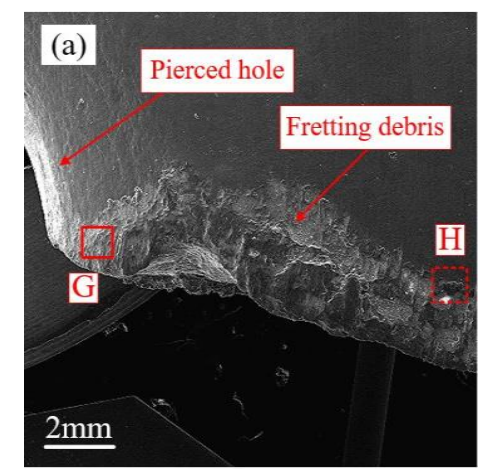

(a) Fretting wear on fractured locked sheet

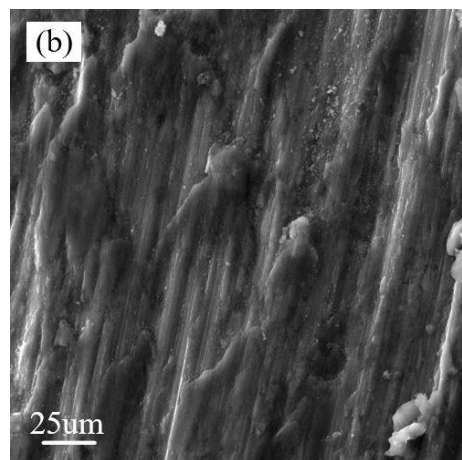

(b) Fretting debris in region $\mathrm{G}$

Fig. 14. A typical locked sheet fracture surface at low load level

Massive fretting debris in fretting region II as marked in Fig. 9 was generated near the locked sheet fracture, as indicated in Fig. 14(a). It is noteworthy that the fretting debris near the fracture can only be observed at a low load level. Fig. 14(b) shows the severe marks of sliding and abrasion in region $\mathrm{G}$ that arose from serious fretting wear between both sheets. A boundary region $\mathrm{H}$ between the sheet surface and fretting area labelled in Fig. 14(a) was investigated using a deeper EDX analysis, as illustrated in Fig. 15. It is clearly shown from the distribution that a large majority of $\mathrm{Al}$ and $\mathrm{O}$ are concentrated in the area of the fretting wear. It could be thought that the elements of $\mathrm{Al}$ and $\mathrm{O}$ were dropped from both sheets owing to the fretting wear, and subsequently 
oxidised to the $\mathrm{Al}_{2} \mathrm{O}_{3}$ (Zhao et al., 2017). At a low load level, the fretting wear in region II assuredly correlated with the locked sheet fractured along the button. The crack propagation along the button was accelerated by the fretting wear, and the propagation rate was higher than that through the button. Ultimately, the locked sheet was broken along the button at a low load level.
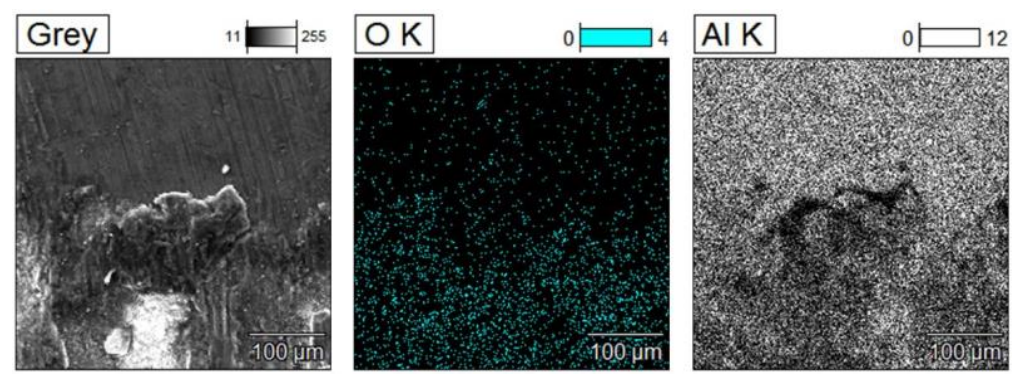

Fig. 15. Energy spectrum of region H marked in Fig. 14(b)

\section{Conclusions}

The SPR process for the aeronautical material of 1420 Al-Li alloy was studied here. The mechanical performances and fretting mechanisms of similar SPR joints in 1420 Al-Li alloys (AL1420 joints) were discussed in detail. The primary conclusions of this study are summarised as follows:

(1) The aeronautical material of $1420 \mathrm{Al}-\mathrm{Li}$ alloy sheets can be connected effectively using SPR with the riveting pressure of $190 \mathrm{bar}$, rivet length of $5 \mathrm{~mm}$, rivet hardness of $44 \pm 2 \mathrm{HRC}$.

(2) The average peak load and energy absorption value could reach $6.03 \mathrm{kN}$ and $16.84 \mathrm{~J}$, respectively. Using the VC method, the reliability of the fatigue data was improved. The fatigue property of the AL1420 joints was advantageous compared with the other metal SPR joints. Further, its fatigue limit could reach nearly $1.5 \mathrm{kN}$.

(3) In the static tests, all the joints failed owing to the rivets separating from the locked sheet. The mechanical interlock was damaged and the pierced sheet was torn because of the sustained lap-shear loads. During the fatigue tests, the joints failed, as evident by the locked sheet that fractured through the button or along the button at a high load level or low load level, respectively. The locked sheet was broken with brittle fractures on one side of the button and ductile fractures on the other owing to a continuous cyclic fatigue load.

(4) Severe fretting wear was observed at the contact interface of the rivet tail and locked sheet at a high load level, and between both sheets at a low load level. The fretting wear occurred in different regions with the load level changed.

\section{Acknowledgments}

This research is supported by the National Natural Science Foundation of China (Grant No. 51565023), and the Doctoral Academic Newcomer Award of Yunnan Province (Grant No. 1319880250).

\section{References}

Abrahami, S., de Kok, J., Terryn, H., Mol, J., 2017. Towards Cr (VI)-free anodization of aluminum 
alloys for aerospace adhesive bonding applications: A review, Front. Chem. Sci. Eng. 11 (3), 465-482.

Briskham, P., Blundell, N., Han, L., Hewitt, R., Young, K., 2006. Comparison of self-pierce riveting, resistance spot welding and spot friction joining for aluminium automotive sheet for static strength, SAE Tech. Pap. 2006-01-0774.

Chen, Y., Han, L., Chrysanthou, A., O'Sullivan, J., 2003. Fretting wear in self-piercing riveted aluminium alloy sheet, Wear, 255, 1463-1470.

Di Franco, G., Fratini, L., Pasta, A., 2012. Influence of the distance between rivets in self-piercing riveting bonded joints made of carbon fiber panels and AA2024 blanks, Mater. Des. 35, 342-349.

Durandet, Y., Deam, R., Beer, A., Song, W., Blacket, S., 2010. Laser assisted self-pierce riveting of AZ31 magnesium alloy strips, Mater. Des. 31 (1), S13-S16.

Fratini, L., Ruisi, V. 2009. Self-piercing riveting for aluminium alloys-composites hybrid joints, Int. J. Adv. Manuf. Technol. 43 (1-2), 61-66.

Fu, B., Qin, G., Meng, X., Ji, Y., Zou, Y., Lei, Z., 2014. Microstructure and mechanical properties of newly developed aluminium-lithium alloy 2A97 welded by fiber laser, Mater. Sci. Eng. A 617, 1-11.

Fu, M., Mallick, P., 2003. Fatigue of self-piercing riveted joints in aluminum alloy 6111, Int. J. Fatigue, 25(3), 183-189.

Gao, Z., 1981. Fatigue Behavior Handbook for Aeronautic Metal Materials, Beijing Institute of Aeronautic Material. (in Chinese)

Gibson, B., Ballun, M., Cook, G., Strauss, A., 2015. Friction stir lap joining of 2198 aluminum-lithium alloy with weaving and pulsing variants, J. Manuf. Process. 18, 12-22.

Han, L., Chrysanthou, A., O'Sullivan, J., 2006. Fretting behaviour of self-piercing riveted aluminium alloy joints under different interfacial conditions, Mater. Des. 27(3), 200-208.

Haque, R., Williams, N., Blacket, S., Durandet, Y., 2015. A simple but effective model for characterizing SPR joints in steel sheet, J. Mater. Process. Technol. 223, 225-231.

Haque, R., Durandet, Y., 2016. Strength prediction of self-pierce riveted joint in cross-tension and lap-shear, Mater. Des. 108, 666-678.

Haque, R., 2018. Quality of self-piercing riveting (SPR) joints from cross-sectional perspective: A review, Arch. Civ. Mech. Eng. 18 (1), 83-93.

He, X., Pearson, I., Young, K., 2008. Self-pierce riveting for sheet materials: State of the art, J. Mater. Process. Technol. 199 (1-3), 27-36.

He, X., 2017. Clinching for sheet materials. Sci. Technol. Adv. Mater. 18(1), 381-405.

He, X., Zhao, L., Deng, C., Xing, B., Gu, F., Ball, A., 2015. Self-piercing riveting of similar and dissimilar metal sheets of aluminum alloy and copper alloy, Mater. Des. 65, 923-933.

He, X., Zhao, L., Yang, H., Xing, B., Wang, Y., Deng, C., Gu, F., Ball, A., 2014. Investigations of strength and energy absorption of clinched joints, Comput. Mater. Sci. 94 (11), 58-65.

Huang, L., Bonnen, J., Lasecki, J., Guo, H., Su, X., 2016. Fatigue and fretting of mixed metal self-piercing riveted joint, Int. J. Fatigue, 83, 230-239.

Khanna, S. K., Long, X., Krishnamoorthy, S., Agrawal, H. N., 2006. Fatigue properties and failure characterisation of self-piercing riveted 6111 aluminium sheet joints, Sci. Technol. Weld. Joi. 11(5), 544-549.

Li, D., Chrysanthou, A., Patel, I., Williams, G., 2017. Self-piercing riveting-a review, Int. J. Adv. 
Manuf. Technol. 92 (12), 1-48.

Li, H., Hu, Y., Fu, X., Zheng, X., Liu, H., Tao, J., 2016. Effect of adhesive quantity on failure behavior and mechanical properties of fiber metal laminates based on the aluminum-lithium alloy, Compos. Struct. 152, 687-692.

Liu, X., Lim, Y., Li, Y., Tang, W., Ma, Y., Feng, Z., Ni, J., 2016. Effects of process parameters on friction self-piercing riveting of dissimilar materials, J. Mater. Process. Technol. 237, 19-30.

Liu, Y., He, X., Deng, C., 2017. Self-piercing riveting of metal foam sandwich structures, Mater. Trans. 58 (11), 1532-1537.

Lou, M., Li, Y., Li, Y., Chen, G., 2013. Behavior and quality evaluation of electroplastic self-piercing riveting of aluminum alloy and advanced high strength steel, ASME J. Manuf. Sci. Eng. 135 (1), 011005.

Mucha. J., 2013. The effect of material properties and joining process parameters on behavior of self-pierce riveting joints made with the solid rivet, Mater. Des. 52 (24), 932-946.

Porcaro, R., Hanssen, A., Langseth, M., Aalberg, A., 2006. An experimental investigation on the behaviour of self-piercing riveted connections in aluminium alloy AA6060, Int. J. Crashworthiness 11 (5), 397-417.

Rao, H., Kang, J., Huff, G., Avery, K., 2018. Impact of specimen configuration on fatigue properties of self-piercing riveted aluminum to carbon fiber reinforced polymer composite, Int. J. Fatigue, $113,11-22$.

Rioja, R., Liu, J., 2012. The evolution of Al-Li base products for aerospace and space applications, Metall. Mater. Trans. A 43A (9), 3325-3337.

Sun, X., Stephens, E. V., Khaleel, Moe A., 2007. Fatigue behaviors of self-piercing rivets joining similar and dissimilar sheet metals, Int. J. Fatigue, 29(2), 370-386.

Tassler, T., Israel, M., Goede, M., Dilger, K., Droder, K., 2018. Robust joining point design for semi-tubular self-piercing rivets, Int. J. Adv. Manuf. Technol. 98 (1-4), 431-440.

Ueda, M., Miyake, S., Hasegawa, H., Hirano, Y., 2012. Instantaneous mechanical fastening of quasi-isotropic CFRP laminates by a self-piercing rivet, Compos. Struct. 94 (11), 3388-3393.

Xie, Z., Yan, W., Yu, C., Mu, T., Song, L., 2018. Improved shear strength design of cold-formed steel connection with single self-piercing rivet, Thin Wall. Struct. 131, 709-717.

Xing, B., He, X., Zeng, K., Wang, Y., 2014. Mechanical properties of self-piercing riveted joints in aluminum alloy 5052, Int. J. Adv. Manuf. Technol. 75 (1-4), 351-361.

Zhang. J., Yang. S., 2014. Self-piercing riveting of aluminum alloy and thermoplastic composites, J. Compos. Mater. 49 (12), 1493-1502.

Zhang, X., He, X., Xing, B., Zhao, L., Lu, Y., Gu, F., A. Ball, 2016. Influence of heat treatment on fatigue performances for self-piercing riveting similar and dissimilar titanium, aluminium and copper alloys, Mater. Des. 97, 108-117.

Zhao, L., He, X., Xing, B., Zhang, X., Cheng, Q., Gu, F., Ball, A., 2017. Fretting behavior of self-piercing riveted joints in titanium sheet materials, J. Mater. Process. Technol. 249, 246-254. 